06,13

\title{
Влияние сильного статического электрического поля и нагрева на характеристики высокочастотного импеданса структур металл-сегнетоэлектрик-полупроводник
}

\author{
() Д.А. Белорусов, Е.И. Гольдман, Г.В. Чучева \\ Фрязинский филиал Института радиотехники и электроники им. В.А. Котельникова РАН, \\ Фрязино, Россия \\ ๑ E-mail: gvc@ms.ire.rssi.ru
}

Поступила в Редакцию 31 января 2022 г.

В окончательной редакции 1 февраля 2022 г.

Принята к публикации 2 фревраля 2022 г.

\begin{abstract}
Проведены исследования влияния нагрева и сильных полевых, но допробойных, воздействий на высокочастотные характеристики импеданса гетероэпитаксиальных структур $\mathrm{Ni}-\mathrm{Ba}_{0.8} \mathrm{Sr}_{0.2} \mathrm{TiO}_{3}-p \mathrm{Si}$ с толщиной сегнетоэлектрика $50 \mathrm{~nm}$. Показано, что независимо от полярности полевого стресса, характеристики сдвигались в сторону положительного смещения, и ширина петель гистерезиса уменьшалась; уровни плато практически оставались неизменными. Нагрев до $121^{\circ} \mathrm{C}$ приводил к изменению уровней верхнего плато характеристик: для емкости он снижался, а для проводимости - поднимался; ветви на петле не просто сужались и сдвигались, а менялись местами по сравнению с исходной зависимостью (реверс петли). Данные результаты могут быть объяснены: при полевом воздействии - генерацией дополнительных электронных состояний, локализованных в буферном слое на границе раздела кремний $-\mathrm{Ba}_{1-x} \mathrm{Sr}_{x} \mathrm{TiO}_{3}$, а при нагреве возникновением эффектов запаздывания вследствие развития флуктуационных процессов, лежащих в основе размытия фазового перехода из сегнетоэлектрического в параэлектрическое состояние.
\end{abstract}

Ключевые слова: высокочастотные полевые характеристики импеданса, полевой стресс, петли гистерезиса, генерация дополнительных локализованных электронных состояний, эффекты запаздывания, флуктуационные процессы, размытый фазовый переход.

DOI: 10.21883/FTT.2022.05.52336.273

\section{1. Введение}

Одно из приоритетных направлений исследований альтернатив окислу кремния - это использование сегнетоэлектрических пленок в качестве изолирующих слоев в электронных устройствах нано диапазона [1]. Уникальные физические свойства сегнетоэлектрических материалов (в частности, высокая и изменяемая под действием внешнего электрического поля диэлектрическая проницаемость) позволяют создавать на основе планарной технологии фактически новый класс устройств хранения и обработки информации [2]. Перспективным сегнетоэлектрическим составом для применения в СВЧтехнике считаются твердые растворы титаната бариястронция $\left(\mathrm{Ba}_{1-x} \mathrm{Sr}_{x} \mathrm{TiO}_{3}\right.$ или BST) [1,2]. Они обладают сегнетоэлектрическими свойствами при температуpax выше комнатной, а эффективная диэлектрическая проницаемость их тонких пленок остается рекордно высокой (в сотни раз выше, чем у $\mathrm{SiO}_{2}$ ) в широком диапазоне температур. Управляющие воздействия на сегнетоэлектрические слои в микро- и наноэлектронных устройствах сопровождаются прикладыванием к толще образца значительных электрических смещений, создающих в BST поля в несколько MV/cm. Подобные нагрузки приводят к называемому по аналогии с объектами из кремния повреждению структур, когда их характеристики высокочастотного импеданса изменяются после по- левого или высокотемпературного воздействий, а затем, за времена порядка суток восстанавливаются к исходному состоянию. Также, по аналогии со структурами на основе кремния для обозначения таких воздействий будем использовать термины полевой и температурный (термический) стрессы. В настоящий момент практически не публикуются работы, посвященные изучению механизмов изменений электрофизических свойств структур металл-BST-Si после полевых и тепловых воздействий. Возникает существенный пробел в знании об устойчивости BST сегнетоэлектриков к полевым и термическим нагрузкам. Поэтому важным направлением исследований является изучение механизмов изменений характеристик структур металл-BST-Si, в результате не приводящих к разрушению типа пробоя полевого и термического стрессов. Этой теме на примере структур металл-BST-pSi с толщинами сегнетоэлектрического слоя $50 \mathrm{~nm}$ и посвящена настоящая работа.

\section{2. Влияние стрессов}

$$
\begin{aligned}
& \text { на высокочастотный импеданс } \\
& \text { структур } \mathrm{Ni}-\mathrm{Ba}_{0.8} \mathrm{Sr}_{0.2} \mathrm{TiO}_{3}-\mathrm{Si}
\end{aligned}
$$

Экспериментальные

исследования

были выполнены на гетероэпитаксиальных структурах $\mathrm{Ni}-\mathrm{Ba}_{0.8} \mathrm{Sr}_{0.2} \mathrm{TiO}_{3}-p \mathrm{Si}$ с площадью полевого электрода 

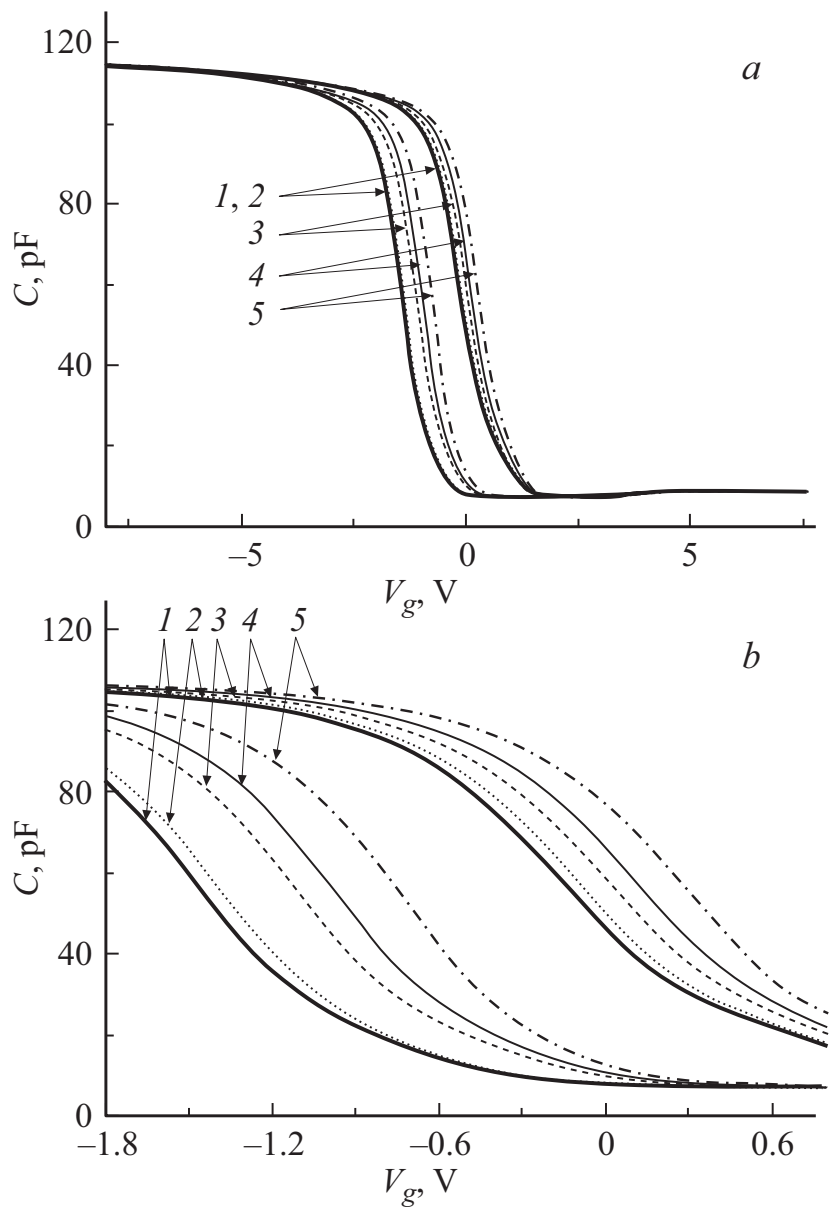

Рис. 1. Изменения вольтемкостных характеристик структур $\mathrm{Ni}-\mathrm{Ba}_{0.8} \mathrm{Sr}_{0.2} \mathrm{TiO}_{3}-\mathrm{Si}$ после полевых воздействий различной амплитуды: $a-$ общий вид кривых, $b-$ петля гистерезиса в увеличенном масштабе. Номера кривых: 1 - исходная, 2 - после стресса $-4 \mathrm{~V}, 3$ - после стресса $-8 \mathrm{~V}, 4$ - после стресса $+4 \mathrm{~V}, 5-$ после стресса $+8 \mathrm{~V}$.

из никеля $S=2.7 \cdot 10^{-4} \mathrm{~cm}^{2}$. Сегнетоэлектрическую пленку толщиной $h=50 \mathrm{~nm}$ наносили методом высокочастотного распыления поликристаллической мишени в атмосфере кислорода на установке Плазма-50СЭ (Россия). Более детально конструкции установок и методика осаждения пленок описаны в $[3,4]$. Измерения импеданса проводились в области температур от комнатной до $121^{\circ} \mathrm{C}$ на частоте $1 \mathrm{MHz}$ с использованием прецизионного измерителя LCR Agilent E4980A, портативного компьютера с доработанным программным обеспечением и специальной камеры, снабженной нагревательным столиком с термостабилизацией. Подробности экспериментальной установки описаны в [5]. На структуру металл-сегнетоэлектрик-полупроводник подавалось напряжение смещения $V_{g}$ от $-8 \mathrm{~V}$ до $+8 \mathrm{~V}$, с шагом $0.005 \mathrm{~V}$ и амплитудой измерительного сигнала $25 \mathrm{mV}$ со скоростью считывания данных 3 точки в секунду.

Выдержка объектов в течение $30 \mathrm{~min}$. при комнатной температуре под постоянными напряжениями от \pm 2 до $\pm 8 \mathrm{~V}$ обеспечивала спектр полевых стрессовых воздействий. Термический стресс реализовывался нагревом образца до $121^{\circ} \mathrm{C}$ и проведением высокочастотных измерений при этой температуре. Результаты опытов представлены на рис. $1-4$.

Полевой стресс приводил к заметным изменениям характеристик высокочастотного импеданса. Как при отрицательных, так и при положительных полярностях стрессового напряжения наблюдались сдвиг характеристик в сторону положительного смещения и уменьшение ширины петель гистерезиса (см. рис. 1,2). При этом уровни плато характеристик практически оставались неизменными. И на высокочастотную емкость, и на проводимость воздействие положительных полярностей сильного электрического поля сказывалось сильнее, чем отрицательных. В таблице приведены экспериментальные данные изменений параметров вольт-фарадных характеристик после различных полевых стрессовых нагрузок.

Термический стресс приводил к более сильным, по сравнению с полевыми, изменениям высокочастотных
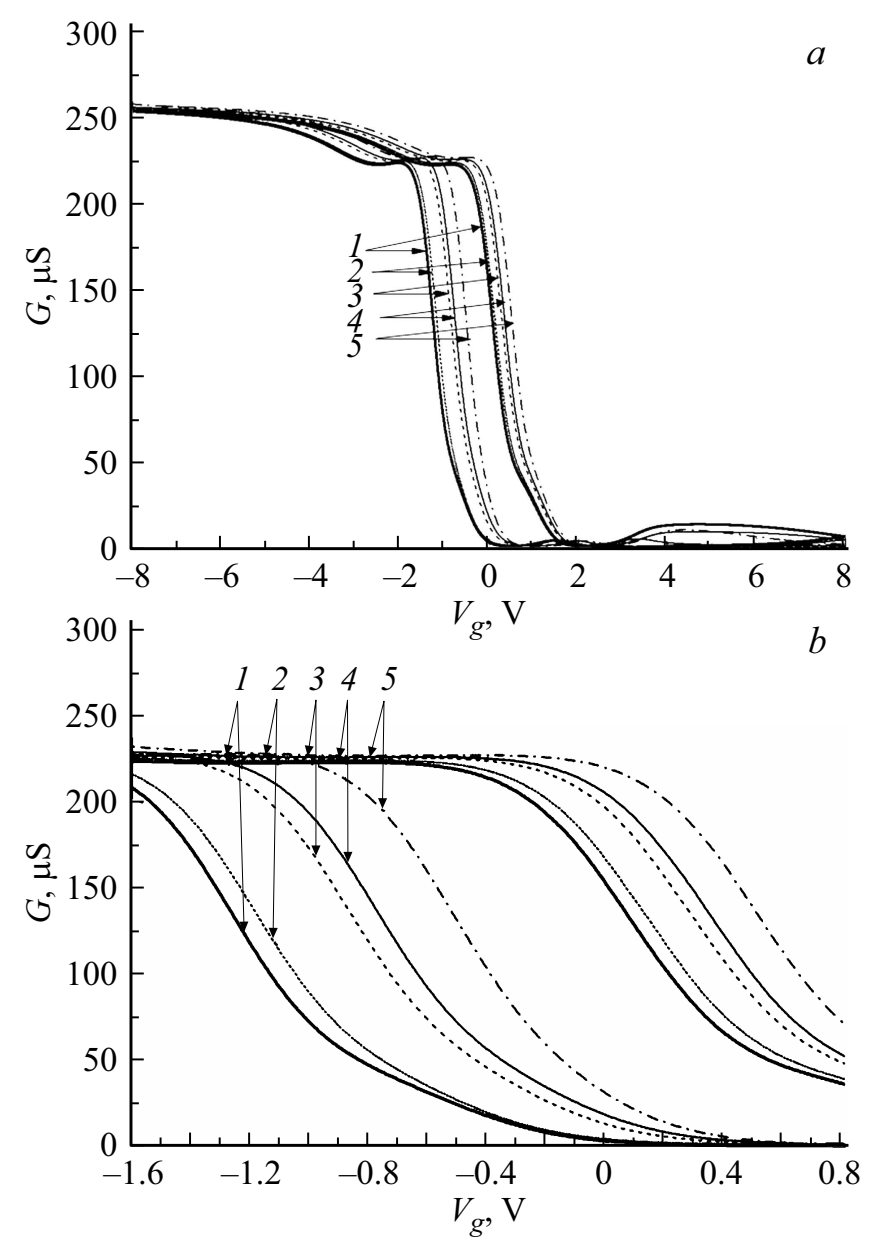

Рис. 2. Влияние полевого стресса на характеристики проводимости структур $\mathrm{Ni}-\mathrm{Ba}_{0.8} \mathrm{Sr}_{0.2} \mathrm{TiO}_{3}-\mathrm{Si} . a-$ общий вид кривых, $b$ - петля гистерезиса в увеличенном масштабе. Номера кривых: $1-$ исходная, $2-$ после стресса $-4 \mathrm{~V}, 3-$ после стресса $-8 \mathrm{~V}, 4-$ после стресса $+4 \mathrm{~V}, 5$ - после стресса $+8 \mathrm{~V}$. 


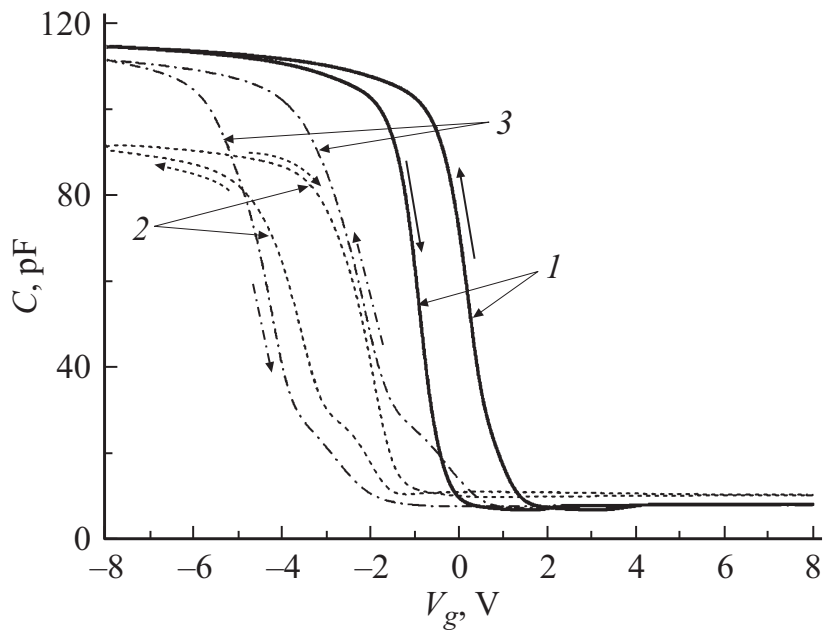

Рис. 3. Изменение вольтфарадной характеристики структуры $\mathrm{Ni}-\mathrm{Ba}_{0.8} \mathrm{Sr}_{0.2} \mathrm{TiO}_{3}-\mathrm{Si}$ при нагреве. Номера кривых: 1 - исходная, 2 - измерения при $121^{\circ} \mathrm{C}, 3-$ измерения сразу после охлаждения до комнатных условий.

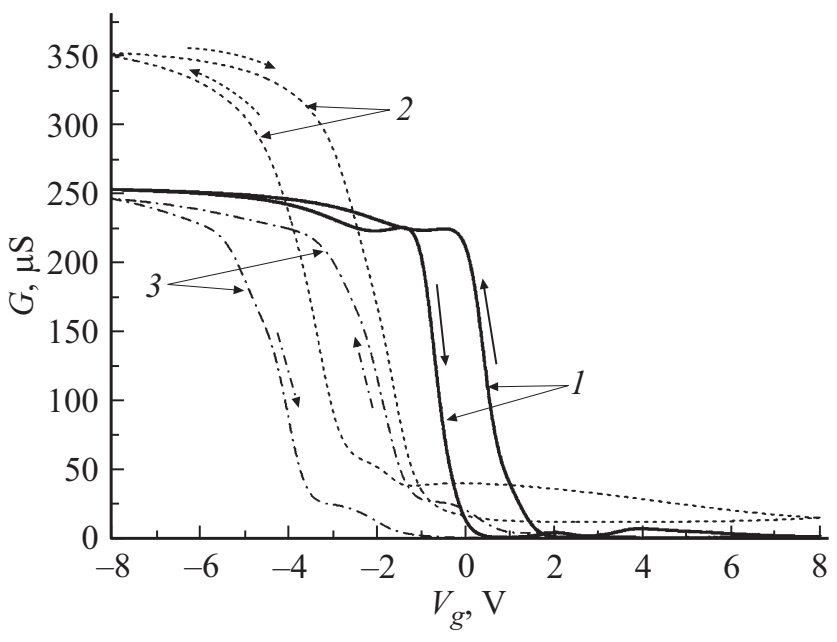

Рис. 4. Изменение характеристик проводимости структуры $\mathrm{Ni}-\mathrm{Ba}_{0.8} \mathrm{Sr}_{0.2} \mathrm{TiO}_{3}-\mathrm{Si}$ при нагреве. Номера кривых: 1 - исходная, 2 - измерения при $121^{\circ} \mathrm{C}, 3-$ измерения сразу после охлаждения до комнатных условий.

характеристик импеданса, см. рис. 3, 4. Кривые не только сдвигались, но и изменялся уровень верхнего плато: для емкости он снижался, а для проводимости поднимался. Ветви на петле характеристики, измеренной при $121^{\circ} \mathrm{C}$, не просто сужались, а менялись местами по сравнению с исходной зависимостью, см. рис. 3 (реверс петли).

\section{3. Обсуждение результатов}

По аналогии с классическими кремниевыми структурами металл- $\mathrm{SiO}_{2}-\mathrm{Si}$ картина изменения высокочастотных характеристик импеданса объектов металл-сегнетоэлектрик-полупроводник после продолжительной
Изменения вольт-фарадной характеристики образца в результате полевого стресса. (Ширина и сдвиг петли гистерезиса определялись на половине высоты перепада характеристики на уровне $60 \mathrm{pF}$. В качестве сдвига принималось изменение положения левой ветви вольт-емкостной зависимости)

\begin{tabular}{l|c|c|c|c|c}
\hline & \multicolumn{5}{|c}{ Величина полевого воздействия } \\
\cline { 2 - 6 } & $\begin{array}{c}\text { Исходная, } \\
\text { без стресса }\end{array}$ & $-4 \mathrm{~V}$ & $-8 \mathrm{~V}$ & $+4 \mathrm{~V}$ & $+8 \mathrm{~V}$ \\
\hline $\begin{array}{l}\text { Ширина петли } \\
\text { гистерезиса, В }\end{array}$ & 1.32 & 1.30 & 1.145 & 1.11 & 1.03 \\
\hline $\begin{array}{l}\text { Сдвиг петли } \\
\text { гистерезиса, В }\end{array}$ & - & 0.069 & 0.37 & 0.47 & 0.70
\end{tabular}

выдержки в сильном электрическом поле может быть объяснена образованием в результате стрессов на контакте BST-кремний дополнительных локализованных электронных состояний [6-8]. Данный контакт имеет сложный характер и содержит тонкий (несколько nm) буферный слой с естественным (native) окислом кремния, прилегающий непосредственно к Si. Известно, что на границе раздела $\mathrm{Si}-\mathrm{SiO}_{2}$ имеются так называемые оборванные связи кремния [9], которые не только перезаряжаются при изменении потенциала, но и их концентрация увеличивается в процессе воздействия сильным электрическим полем. Причем увеличение числа локализованных электронных состояний происходит при обеих полярностях электрического воздействия. В работах [10-11] экспериментально показано, что в связи с перезарядкой электронных ловушек в буферном переходном слое между сегнетоэлектриком и полупроводником, эффект поля на контакте $\mathrm{BST}-\mathrm{Si}$ проявляется крайне слабо. Практически все внешнее поле экранируется зарядами в переходном слое, падение внешнего напряжения на полупроводник мало, высокочастотная емкость структуры металл-BST-Si определяется кремнием, а изгиб зон в нем отклоняется от состояния плоских зон всего на несколько $k T / q$ во всем наблюдаемом диапазоне смещений, где $k$ - константа Больцмана, $T$ - абсолютная температура, $q$ - элементарный заряд. Присущая высокой концентрации неупорядоченных ловушек буферного слоя $U$-образная энергетическая плотность локализованных состояний с минимумом в окрестности плоских зон кремния обусловливает резкое замедление повышения при обогащении и уменьшения при обеднении падения внешнего напряжения на полупроводнике. В свою очередь, это замедление приводит: во-первых, к образованию никак не связанных с сильным обогащением или инверсией поверхности полупроводника, двух плато полевых зависимостей высокочастотных характеристик импеданса структур металл-BST-Si, a во-вторых, к расположению петель гистерезиса на данных характеристиках в окрестности состояния плоских зон полупроводника. Полевое воздействие приводит к увеличению энергетической плотности локализованных 
в переходном слое электронных состояний, и модуль их заряда возрастает. Соответственно, при том же смещении должна уменьшиться абсолютная величина заряда поверхностной области полупроводника, связанная с перетеканием свободных носителей для экранирования внешнего поля. Таким образом, модуль изгиба зон в кремнии уменьшается, а падение напряжения на слое сегнетоэлектрика (при том же смещении) возрастает.

В сегнетоэлектрической фазе петли гистерезиса характеристик объекта металл-BST-Si не описываются в одномерных представлениях, а обусловлены разными для каждого направления изменениями внешнего смещения со временем перестройки доменной системы. Расположение ветвей характеристик высокочастотного импеданса по оси напряжений не симметрично относительно начала отсчета. Это связано с контактной разностью потенциалов между полевым электродом и кремнием, а также с концентрацией встроенного заряда в сегнетоэлектрическом промежутке. Поэтому при одном и том же значении емкости на одной из ветвей (в нашем случае на левой, см. рис. 1) падение внешнего напряжения будет по модулю больше, чем на другой. Соответственно, и реакция на приращение в результате полевого стресса заряда локализованных в буферном слое электронных состояний у данной ветви будет больше, чем у другой. Наблюдательно это сводится к большему сдвигу левой петли, чем правой - отсюда и смещение характеристик в сторону положительных внешних напряжений и уменьшение ширины петель гистерезиса.

Нагрев от комнатной температуры до $121^{\circ} \mathrm{C}$ переводит пленку BST в параэлектрическое состояние. В этой фазе стационарные петли сегнетоэлектрического гистерезиса на характеристиках должны исчезать. Наблюдаемый реверс петель, см. рис. 3, свидетельствует о проявлении эффектов запаздывания в динамических кривых представления измеряемых величин, как функций внешнего напряжения. Об этом же говорят и отклонения формы характеристик, измеренных сразу после охлаждения, от исходных. Температура $121^{\circ} \mathrm{C}$ близка к области размытого фазового перехода пленки BST из сегнетоэлектрического в параэлектрическое состояние. Поэтому на роль источников эффектов запаздывания вполне могут претендовать продолжительные флуктуационные процессы, обусловленные дефектами структуры и объясняющие размытие фазового перехода $[12,13]$.

\section{4. Заключение}

Из результатов настоящей работы следует, что механизмы возникновения последствий полевого и термического воздействий на изолирующую пленку BST различны. В первом случае это генерация дополнительных электронных состояний, локализованных в буферном слое на границе раздела кремний- $\mathrm{Ba}_{1-x} \mathrm{Sr}_{x} \mathrm{TiO}_{3}$. Во втором - проявление эффектов запаздывания вследствие развития флуктуационных процессов, лежащих в основе размытия фазового перехода из сегнетоэлектрического в параэлектрическое состояние. Естественно, что детальное изучение этих явлений потребует разных подходов к постановке экспериментальных работ. В первом случае это привлечение методов определения локализованного в буферном слое заряда электронных ловушек. Во втором случае, два пути: проведение измерений временных зависимостей характеристик импеданса после ступенчатого изменения внешнего напряжения и применение различных скоростей динамической развертки результатов фиксации данных по смещению.

Отметим важную особенность тонкопленочных структур металл-сегнетоэлектрик-полупроводник. В подавляющем большинстве случаев у них используется единая кремниевая подложка для разных сегнетоэлектрических материалов. Это означает, что проявления полевого воздействия на данные объекты должны носить общий характер, в большей степени зависеть от свойств буферного слоя на контакте изолятор-кремний и в меньшей - от вида используемого сегнетоэлектрика.

\section{Финансирование работы}

Работа выполнена в рамках государственного задания и частично поддержана Российским фондом фундаментальных исследований (проект РФФИ № 19-29-03042-мк).

\section{Конфликт интересов}

Авторы заявляют, что у них нет конфликта интересов.

\section{Список литературы}

[1] V.R. Mudinepalli, L. Feng, W.-C. Lin., B.S. Murty. J. Adv. Ceram. 4, 46 (2015).

[2] К.А. Воротилов, В.М. Мухортов, А.С. Сигов. Интегрированные сегнетоэлектрические устройств. / Под ред. А.С. Сигова. Энергоатомиздат, М. (2011). 175 с.

[3] М.С. Иванов, М.С. Афанасьев. ФТТ 51, 7, 1259 (2009).

[4] Д.А. Киселев, М.С. Афанасьев, С.А. Левашов, Г.В. Чучева. ФТТ 57, 6, 1134 (2015).

[5] Е.И. Гольдман, А.Г. Ждан, Г.В. Чучева. ПТЭ 6, 110 (1997).

[6] J. Nissan-Cohen. Appl. Surf. Sci. 39, 1-4, 511 (1989).

[7] T.R. Oldham, F.B. McLean, H.E. Boesch, J.M. McCarrity. Semicond. Sci. Technol. 4, 12, 986 (1989).

[8] M.L. Reed. Semicond. Sci. Technol. 4, 12, 980 (1989).

[9] В.А. Гриценко. УФН 52, 9, 869 (2009).

[10] E.I. Goldman, G.V. Chucheva, D.A. Belorusov. Ceram. Int. 47, 15, 21248 (2021).

[11] Д.А. Белорусов, Е.И. Гольдман, Г.В. Чучева. ФТТ 63, 11, 1887 (2021).

[12] А.П. Леванюк, В.В. Осипов, А.С. Сигов, А.А. Собинин. ЖЭТФ, 76, 1, 345 (1979).

[13] А.П. Леванюк, Б.В. Мощинский, А.С. Сигов. ФТТ 23, 7, 2037 (1981).

Редактор Т.Н. Василевская 